Encuentro No. 104, 38-52, 2016

\title{
El movimiento social nicaragüense por la defensa de la tierra, el agua y la soberanía ${ }^{1}$
}

\section{Luis H. Serra Vázquez*}

\section{Recibido: junio de 2016 / Aceptado: julio de 2016}

En primer lugar, se describen las características del proyecto del canal interoceánico y otras inversiones concedidas por el gobierno de Nicaragua a una empresa extranjera por un periodo de 116 años en una zona de 3,423.9 $\mathrm{km}^{2}$, donde viven 119,200 personas. En segundo lugar, se expone el surgimiento y desarrollo del movimiento campesino hasta la fecha (17-06-2016), las acciones realizadas, la modalidad organizativa, las alianzas y las respuestas del gobierno. Luego se presenta un análisis sociológico de los factores históricos y coyunturales que permiten comprender la conformación de este movimiento en un contexto de restricción de libertades públicas. Por último, se plantean algunas reflexiones sobre los resultados, retos y perspectivas de este movimiento social.

Palabras clave: movimiento social / coyuntura política en Nicaragua / resistencias al capital transnacional en Centroamérica / megaproyectos en América Latina

\section{Introducción}

El artículo presenta un resumen de una investigación sobre el Movimiento Campesino e Indígena surgido en 2014 en Defensa de la Tierra, el Agua y la Soberanía Nacional (MCITAS) que está siendo amenazado por el mega proyecto del canal interoceánico de la empresa china Hong Kong Nicaragua Development (HKND), aprobado por el gobierno de Nicaragua. Los datos presentados se basan en fuentes de información documental (reportajes, informes, estudios) y entrevistas a

1 Una versión preliminar de este artículo fue presentada en el congreso de ALAS Nov. 2015. Se ha actualizado la información al 15-6-16 y ampliado su análisis para esta publicación y para presentarse posteriormente como ponencia en el congreso de ACAS, Universidad Centroamericana, Managua, de 11 al 14 de octubre de 2016.

- Departamento de Ciencias Sociales, Universidad Centroamericana (UCA), Managua. Correo electrónico: luishectorserra@gmail.com. Teléfono: 505-86544999. 
líderes, miembros y aliados del movimiento social, reportajes periodísticos, así como en la observación de acciones realizadas.

Los objetivos de este artículo son, en primer lugar, presentar la evolución, los fines y la organización de este nuevo movimiento social. En segundo lugar, analizar a la luz de las teorías sociológicas contemporáneas, los factores que han influido en el desarrollo del movimiento, sus características distintivas y el impacto potencial de su accionar.

Según Eyerman y Jamison un movimiento social es un "grupo de individuos reunidos con el propósito común de expresar de forma publica el descontento sentido subjetivamente y de cambiar lo que se percibe como los fundamentos sociales y políticos de tal descontento" (Eyerman \& Jamison, 1991, p.43) En otros términos un movimiento social es un actor colectivo conformado por personas que comparten una identidad y unos objetivos de transformación social o de oposición a un cambio que afecte sus condiciones de vida, y que implementan diversas acciones con un nivel organizativo flexible y dinámico (Serra, 2003).

Este estudio plantea que para comprender el surgimiento y dinámica de este movimiento social conformado por campesinos e indígenas, hay que tener en cuenta factores históricos y estructurales de carácter económico, político y cultural, en conjunto con acontecimientos coyunturales que precipitaron la movilización y organización de la población rural que habita en los municipios afectados por el mega proyecto, en defensa de sus tierras, sus derechos y su forma de vida.

\section{El proyecto del canal interoceánico}

En junio de 2013 la Asamblea Nacional aprobó la ley 840 que le otorga la concesión a la empresa china HKND para la construcción y operación de un canal interoceánico por 50 años, más 16 años para la gestión financiera y la construcción, plazo que puede extenderse por otros 50 años si desea la compañía. En Nicaragua la empresa se ha registrado bajo otro nombre en sociedad con otros inversionistas secretos. El interés de HKND es lucrarse con un canal que permita bajar los costos de transporte marítimo de materias primas que compran los países asiáticos de América Latina y de mercaderías que ellos venden en esta región (Academia de Ciencias de Nicaragua, 2014).

La ley 840 y el Acuerdo de Concesión fueron introducidos por el Presidente Ortega a la Asamblea Nacional siendo aprobados por la mayoría parlamentaria del FSLN en pocos días y sin la debida consulta. Además del canal, la concesión comprende otros proyectos: dos puertos, dos aeropuertos, dos zonas de libre comercio, un ferrocarril y un oleoducto, un lago artificial de $395 \mathrm{~km}^{2}$, y una central hidroeléctrica con su embalse de $48.5 \mathrm{~km}^{2}$. La ley deja abierta la posibilidad de otras inversiones que requiera HKND, así se ha propuesto construir cuatro centros turísticos de alcance internacional. La ley declara de "interés público" la expropiación de cualquier bien inmueble, sea privado, estatal o de una comunidad indígena, y establece un procedimiento rápido de expropiación. Las propiedades estatales serán donadas y las privadas pagadas al valor catastral o al precio de mercado si es menor (Asamblea Nacional, 2013). 
Encuentro №. 104, 38-52, 2016

El área total que ocuparán los proyectos de HKND será de $3,423.9 \mathrm{~km}^{2}$, lo cual representa el 27.5\% del territorio de los 13 municipios afectados en la región sur del país. Dentro de esta amplia zona, existen 282 poblados que suman 24,100 hogares donde viven 119,200 personas. En este territorio administrado por HKND no regirán las leyes del país ni tendrán competencia los gobiernos municipales, regionales, indígenas o el nacional. Se han presentado 34 recursos por inconstitucionalidad de la ley 840 ante la Corte Suprema de Justicia, pero fueron rechazados (Centro Humboldt, 2014; Red de Desarrollo Local, 2015).

El canal tendrá una longitud de $259 \mathrm{~km}$ desde el Océano Pacífico hasta el Mar Caribe, atravesando $104 \mathrm{~km}$ del lago Cocibolca, con una profundidad de 29 $\mathrm{m}$ y un ancho de $230 \mathrm{~m}$ además de una zona restringida de 5 a $10 \mathrm{~km}$ a cada lado del canal. Sólo en dos puntos se permitirá cruzar el canal: un puente en la carretera panamericana en Rivas y un ferry en San Miguelito (HKND, 2014). Diversos estudios han identificado los principales efectos adversos de estos proyectos, incluyendo el estudio de impacto social y ambiental hecho por la firma consultora Environmental Resources Management (ERM) contratada por HKND (HKND-ERM, 2015).

En síntesis se destacan los siguientes efectos adversos:

* El desplazamiento forzoso de unas 120,000 personas sin que se conozca un plan de reasentamiento y de alternativas económicas, el Acuerdo de Concesión exime a HKND y al gobierno de ese deber.

* La división de los municipios y del país en dos zonas separadas impidiendo el tránsito de personas, mercaderías y especies animales.

* La pérdida de la producción agropecuaria de esa zona repercutirá en los ingresos de las familias campesinas y en el abastecimiento alimentario nacional.

* La destrucción de la infraestructura existente en esas comunidades: viviendas, iglesias, centros de salud, escuelas, cementerios, empresas, parques, centros deportivos, casas comunales, etc.

* La afectación de siete áreas protegidas, la pérdida de 193,000 ha de bosques, la contaminación del lago Cocibolca $\left(8.624 \mathrm{~km}^{2}\right)$ una fuente de agua, pesca y turismo para los municipios cercanos.

* La pérdida del patrimonio cultural existente en esas zonas donde viven pueblos originarios y la aculturación forzada con miles de inmigrantes que vendrán de otros países.

El proyecto del canal interoceánico se inscribe dentro de un ciclo de expansión del capitalismo global luego de la crisis del 2008-2009, que se expresa en América Latina a través de mega proyectos de inversión promovidos por compañías transnacionales en búsqueda de materias primas y combustibles para las potencias hegemónicas. También se trata de aprovechar la mano de obra barata de la región en un contexto de desregulación laboral y exoneraciones fiscales en función de maximizar sus ganancias, destacándose el rol protagónico de las inversiones chinas (Osava, 2013; Cardenal \& Araujo, 2012). 


\section{Surgimiento y desarrollo del movimiento campesino}

Luego de la aprobación de la concesión canalera, el gobierno y la empresa HKND lanzaron una intensa campaña de propaganda destacando los beneficios del proyecto para el desarrollo del país y el combate a la pobreza a través de la creación de miles de empleos, las inversiones con efecto multiplicador en la economía, la inserción de Nicaragua en el comercio internacional y los réditos de operación del canal. El gobierno planteó que durante los cinco años de construcción el PIB crecería a un promedio de $11.67 \%$ anual, el empleo formal un $28 \%$ anual, además de recibir U\$100 millones en 10 años y el $1 \%$ de las acciones anualmente hasta ser socio mayoritario luego de medio siglo (Oquist, 2013).

Gran parte de la población del país aceptó esta visión optimista del proyecto gracias al control gubernamental de la mayoría de los medios de comunicación y la autocensura de otros medios para evitar represalias. Menor divulgación tuvo una visión crítica del proyecto presentada por otros actores como la Academia de Ciencias, el Grupo de Organizaciones Civiles "Cocibolca", algunos medios de comunicación y partidos opositores. Los foros realizados por el Grupo Cocibolca en diversos municipios que atravesaría el canal despertaron muchas inquietudes al exponer los estudios realizados sobre las repercusiones ambientales del proyecto y sobre el marco jurídico de la concesión (Centro Humboldt, 2014; López Baltodano, 2014). Igualmente, la distribución y estudio de la ley 840 contribuyó al despertar del movimiento social como lo ha expresado Francisca Ramírez, lideresa de La Fonseca, Municipio de Nueva Guinea, y Vice Coordinadora del Consejo Nacional del MCITAS: "La organización de nosotros surge a través de conocer la ley 840, comenzamos a leerla y vimos que el chino era privilegiado porque se le había regalado Nicaragua".

El factor detonante de la movilización social fue el censo de propiedades y población que comenzó a realizar HKND en julio de 2014 a lo largo de la franja territorial que ocuparía el canal y los otros proyectos. Apoyado por fuerzas del ejército o la policía, un equipo técnico chino penetró en las fincas y viviendas de la población -con o sin autorización de sus dueños-para medir los terrenos, fotografiar las viviendas y levantar una lista de habitantes, sin dar ninguna explicación. Esta violación de la propiedad desató la indignación de la población local que se movilizó para expulsar al equipo de HKND de sus comunidades.

El primer estallido en repudio de la intrusión extranjera en sus tierras ocurrió en agosto de 2014 en las comunidades de Tolesmayda y Obrajuelo, en el departamento de Rivas, donde la población era en su mayoría de afiliación sandinista y de origen náhuatl. El líder local Ronald Iván Henríquez dijo: "Yo me siento traicionado por el comandante Daniel, yo soy sandinista, pero voy a luchar por que se respeten nuestros derechos". Días después se realizaron marchas en varias comunidades cercanas para manifestar su rechazo al proyecto del canal y a la expropiación de sus tierras a pesar de la intimidación de la policía y las fuerzas del régimen. Como explicó Octavio Ortega, miembro del Consejo Nacional MCITAS: "La primera marcha fue de 400 personas en Buenos Aires. Había tres cordones de Policía y tres camionetas del partido de gobierno llenas de trabajadores del Estado, pero vieron a una población 
Encuentro No. 104, 38-52, 2016

decidida y más de 100 motos con sus banderas azul y blanco".

Estas marchas lograron vencer el aislamiento y el temor de las familias campesinas para expresar colectivamente sus demandas en espacios públicos, y despertaron la movilización solidaria de la población de otros municipios que padecían los mismos agravios y tenían iguales demandas. Sin duda, algunos medios de comunicación jugaron un rol importante al ampliar el horizonte del campesinado disperso transmitiendo la experiencia de esos primeros manifestantes, lo cual generó solidaridad y motivó la acción ciudadana. En los meses de octubre y noviembre se formaron comités locales y se realizaron doce movilizaciones multitudinarias en diferentes municipios como El Tule, San Miguelito, Río San Juan, Nueva Guinea, Moyogalpa, Tola y Bluefields, en las cuales participaba gente de distinta afiliación política y religiosa bajo una misma bandera: la defensa de sus tierras y sus comunidades.

El 26 de noviembre de 2014 se realizó un encuentro nacional de representantes de los Comités de Tierra de los distintos municipios, en el cual se decidió conformar un Consejo Nacional en Defensa de la Tierra, el Lago y la Soberanía Nacional, como instancia de coordinación y representación del movimiento con el fin de lograr la derogación de la ley 840. Así mismo se acordaron algunas acciones cívicas a emprender, como fue la formación de Comités en todas las comunidades y municipios afectados por el canal, y la organización de una marcha nacional en la capital.

El 10 de diciembre de 2014 ocurrió la primera movilización nacional en Managua, en conmemoración del Día Internacional de los Derechos Humanos, con la participación de miles de personas, en su mayoría campesinos de los municipios afectados a pesar de las medidas del gobierno para impedir el traslado de participantes y del largo viaje que debían emprender muchos para llegar hasta la capital. El Dr. Gonzalo Carrión, director del CENIDH, señaló: "En el día de los derechos humanos, el Gobierno montó operativos de intimidación, registro y requisa, con retenes en las carreteras para no dejar pasar las caravanas de manifestantes".

Además de las marchas públicas, el MCITAS realizó visitas a otros departamentos del país para dar a conocer la ley 840 y formar comités de apoyo, participó en la recolección de 60,000 firmas demandando la derogación de la ley 840, en declaraciones públicas a medios nacionales e internacionales, y en una campaña internacional online de solidaridad vía AVAAZ. Al mismo tiempo el MCITAS tejió alianzas con organizaciones y líderes dispuestos a apoyar sus reivindicaciones, tales como organizaciones civiles y religiosas, medios de comunicación, centros de derechos humanos, partidos políticos y organizaciones ambientalistas internacionales.

Frente a las demandas públicas del movimiento campesino, el gobierno optó por desechar el diálogo y HKND anunció que el 22 de diciembre de 2014 comenzarían las obras de construcción del canal en Tola, organizando un evento propagandístico fuertemente resguardado por el Ejército. Ante la intransigencia gubernamental, el movimiento decidió escalar las protestas con cortes del tránsito en algunas carreteras - una acción muy común en el país- con el fin de llamar la atención pública e impedir la entrada del personal de HKND en sus comunidades. El 17 de diciembre de 2014 comenzaron los tranques de carreteras en El Tule, Nueva Guinea, Rivas y Río San Juan, con la participación de cientos de campesinos. Como 
dijo Orlando Campos, líder campesino de Nueva Guinea: "Tenemos un tranque escalonado por 20 minutos para hacer conciencia a la población, aunque hay incertidumbre y temor, estamos decididos a defender nuestro patrimonio".

El 23 y 24 de diciembre de 2014 las protestas fueron acalladas por la fuerza desplegada por la Brigada Antimotines de la Policía y las fuerzas del Ejército, con un saldo de decenas de campesinos heridos y otros que fueron encarcelados y torturados en la tristemente célebre prisión "El Chipote" en Managua, donde los Somoza recluían a sus adversarios. Frente a la represión desatada en Navidad del 2014, se alzó la voz del obispo Silvio Báez: "En nombre de la paz anunciada en el nacimiento de Jesús, ¡basta de represión contra campesinos y libertad para los detenidos! Condeno con tristeza y dolor la represión violenta contra campesinos al sur de Nicaragua". Un testigo del brutal accionar contra los campesinos de El Tule, el médico y teniente del Ejército Yadiel Montiel que estaba de vacaciones, fue encarcelado por criticar la represión policial acusado de "conducta indecente, deshonesta; que afecta el decoro de la institución”, un acto violatorio del derecho de libre expresión (CENIDH, 2014).

La respuesta violenta del gobierno en Navidad y la presencia militar permanente en las comunidades, no detuvo al MCITAS ni amilanó a sus líderes. Las marchas de protesta continuaron desde el 28 de diciembre en Puerto Príncipe y durante enero 2015 se extendieron a El Tule, San Miguelito, Río San Juan, Matiguás, Agua Zarca, el Jícaro y el Almendro. A fines de enero se presentó la demanda del movimiento en la reunión de la Comunidad de Estados Latinoamericanos y Caribeños (CELAC), realizada en Costa Rica, y en marzo se planteó una demanda contra el Estado de Nicaragua ante la Comisión Interamericana de Derechos Humanos (Consejo Nacional, 2015).

En las comunidades donde el ejército ocupó las escuelas como su base de operación, se suspendieron las clases y se realizaron marchas de niños y padres reclamando el desalojo de sus centros educativos. En su mensaje de Cuaresma la Conferencia Episcopal manifestó: "Nos preocupa ciertamente la dimensión ecológica de este proyecto... Nos preocupa el pueblo, los campesinos pobres y los medianos productores de la zona afectada por este proyecto, quienes viven con zozobra e incertidumbre de cara al futuro: no tienen certeza de que recibirán el precio justo por sus tierras; saben que pueden ser víctimas de desplazamientos forzosos; no saben adónde irán..." (Conferencia Episcopal de Nicaragua, 8-3-2015).

En el período de febrero a mayo de 2015 se realizaron 22 acciones de protesta en distintas comunidades y municipios, hasta que el 10 de junio se realizó la segunda marcha nacional en Juigalpa, donde miles de campesinos se unieron para expresar sus demandas mediante carteles y consignas que decían: "No al canal. No a la Dictadura. No a la destrucción del Lago. No a la Ley 840!. "¿Qué quieren los campesinos? Que se vayan los chinos". "Nicaragua vale más que un canal". ¿Qué decimos a Ortega? ¡Que la Patria no se entrega!". "Nuestra tierra no está en venta”.

A fines de septiembre de 2015 la empresa Environmental Resources Management (ERM), contratada por HKND, publicó su estudio de impacto social y ambiental, en el cual señala que el proyecto tendría impactos sociales y ambientales significativos al afectar áreas protegidas, tierras indígenas y el Lago de Nicaragua. El estudio reconoce que el proceso de expropiación de tierra y reubicación de población 
Encuentro No. 104, 38-52, 2016

no cumple con las normas internacionales. El amplio estudio realizado por expertos internacionales recomendó realizar diversas investigaciones complementarias para determinar su viabilidad socio ambiental y planteó un sinnúmero de medidas de mitigación (HKND-ERM, 2015).

Ante la sequía que afectaba a muchas comunidades del "corredor seco" en octubre 2015 el Consejo Nacional del movimiento envió 800 qq de granos básicos a cinco municipios de Nueva Segovia, pero la Policía impidió esa entrega y obligó a retornar los alimentos. El 2 de octubre ocurrió la primera marcha en Bluefields contra el Canal y el 28 de ese mes el movimiento realizó la $3^{\circ}$ marcha nacional en Managua a pesar de los tranques en las carreteras por parte de la Policía y grupos sandinistas. El gobierno convocó en Managua ese mismo día a una movilización de empleados y estudiantes, la marcha del movimiento social no pudo avanzar y fue agredida resultando ocho personas heridas.

A inicios de 2016 el Consejo Nacional impulsó una iniciativa de ley para presentar a la Asamblea Nacional a fin de derogar la ley 840 basada en el artículo 140 de la constitución política. Se recogieron 28,698 firmas de las cuales 7,000 fueron debidamente notariadas y se presentaron el 7 de abril de 2016, pero fueron rechazadas por la Secretaría del parlamento. Como dijo Medardo Mairena, miembro del Consejo Nacional: "La constitución nos da el derecho de juntar firmas para mandar una iniciativa que derogue la ley 840 , pero la rechazaron, desconocen nuestros derechos y violan la constitución. La policía ha llegado a catear las casas de líderes del movimiento a cualquier hora y sin orden judicial" (Programa Esta Noche, 25-4-15) En esos días, el Tribunal Latinoamericano del Agua condenó al Estado de Nicaragua por violación del derecho internacional de protección ambiental con el proyecto del canal y recomendó respetar los derechos humanos, en particular el derecho al agua (Tribunal Latinoamericano del Agua, 2016).

Las actividades de protesta continuaron en distintos municipios y el 22 de abril de 2016, en celebración del Día Internacional de la Madre Tierra, se realizó en Nueva Guinea la marcha 65 y la cuarta a nivel nacional con la participación de miles de campesinos e indígenas de distintos municipios. Fue la primera ocasión en que no hubo represión policial, tal como lo había solicitado Amnistía Internacional. Luego del evento, Nemesio Mejía, miembro del Consejo Nacional, expreso que: "Siempre debió haber sido así porque no se puede impedir que la gente reclame sus derechos... No estamos marchando contra la policía o contra el ejército, marchamos para que deroguen la ley 840 que nos quiere quitar nuestra tierra" (Programa Esta Noche, 25-4-15).

En junio de 2016 el movimiento planteó un recurso de amparo ante la Corte Suprema de Justica (CSJ) por la violación de su derecho a plantear una iniciativa de ley por la Asamblea Nacional y el día 13 se realizó una marcha en El Tule y un plantón en Managua frente a la CSJ pero sólo llegaron 50 campesinos porque los dueños de los buses alquilados fueron amenazados si los transportaban. El grupo portaba una gran manta que decía: "Si no hay justicia para el pueblo, no habrá paz para el gobierno", lema que refleja la indignación del movimiento al cerrarse todas la vías legales de respuesta a sus demandas. Al ser entrevistado, el campesino Pablo Morales de Punta Gorda expresó: "Esta manifestación es otra más pidiéndole al gobierno que, por favor, escuche al pueblo”. Francisca Ramírez, lideresa del 
MCITAS, dijo: "Si no nos escuchan vamos a paralizar el país, porque preferimos morir que entregar nuestras tierras" (La Prensa, 14-06-2016).

Hasta la fecha (20-06-16) el gobierno no ha mostrado voluntad de dialogar y negociar con el MCITAS. Sus respuestas han sido la intervención de las fuerzas armadas y de grupos de choque contra las marchas pacíficas, la persecución de líderes y las ofertas de soborno, la interferencia de los teléfonos, las amenazas a transportistas y empresarios que los apoyan, los intentos de infiltrar y dividir el movimiento, y el corte de inversiones y proyectos gubernamentales en las comunidades participantes. La empresa HKND ha prometido negociar con los dueños de propiedades y pagar el precio de mercado. Sin embargo, la ley 840 no ha sido modificada y se ha intensificado la propaganda oficial en pro del proyecto, aprovechando el control sobre la mayoría de los medios de comunicación.

\section{Participación y organización del movimiento campesino}

En los primeros meses las acciones del MCITAS tenían un carácter local y espontáneo con un nivel mínimo de organización y de elaboración de sus planteamientos. En esta etapa jugaron un rol importante los liderazgos locales que se fueron destacando en las primeras acciones, así como las organizaciones y redes sociales existentes en las comunidades rurales, logrando concitar la adhesión de los pobladores. Diversos estudios sobre los movimientos sociales muestran la importancia de contar con un grupo de líderes comprometidos que asumen riesgos, son capaces de movilizar con su ejemplo y de dar coherencia a las demandas sociales (Ibarra \& Tijerina, 1998).

El bagaje histórico de experiencias adquiridas por ese liderazgo local sumado al apoyo de organizaciones civiles, permitió que en sólo tres meses el MCITAS se articulara en una instancia nacional de coordinación y dirección colectiva. El Consejo Nacional del movimiento está conformado por 18 representantes de distintos territorios, quienes se mantienen en comunicación permanente y se reúnen periódicamente para evaluar la situación y acordar por consenso las acciones a realizar. Los cargos directivos fueron electos por los miembros del Consejo, es decir el Coordinador, la Vice Coordinadora, el Secretario y el Tesorero. Como explicó Medardo Mairena, líder de Punta Gorda, Municipio de Bluefields, y miembro del Consejo Nacional: "En las asambleas en las comarcas fuimos electos para representarlos en esta lucha, comenzamos con Comités Comarcales, luego Municipales y después un Comité Nacional. Poco a poco nos expandimos por todo Nicaragua. Así hemos organizado más de 65 comités, también organizamos grupos de abogados para la defensa jurídica”.

Los Comités de Defensa de la Tierra constituyen una red de células locales que juega un rol fundamental para la vida del movimiento social. Los Comités cumplen diversas funciones: mantener la comunicación con otros Comités y con el Consejo Nacional, organizar las actividades y motivar la participación, recoger las propuestas y los aportes económicos, sensibilizar y captar nuevos participantes. Los representantes de los Comités son electos en una asamblea comunitaria; generalmente son cinco personas: coordinador/a, secretario/a, tesorero/a, comunicador/a y vocal. En todas 
Encuentro No. 104, 38-52, 2016

las comunidades funciona una red de informantes para mantener la comunicación con las bases y para detectar cualquier amenaza. Por ejemplo, luego de su desalojo los técnicos de HKND han intentado continuar el censo de población disfrazados de "brigada médica" pero fueron detectados y expulsados.

Hay que destacar que el MCITAS es autofinanciado, es decir que los gastos de las actividades que realizan son asumidos por sus miembros. Los Comités recogen aportes de las comunidades, de acuerdo a la posibilidad económica de cada productor, para que los delegados puedan participar en las marchas y reuniones. Sin duda, las movilizaciones periódicas han afectado las actividades productivas de los participantes, quienes han mermado las áreas de siembra y las ventas de ganado. Sin embargo, la solidaridad de las familias campesinas ha permitido que algunos miembros asuman el trabajo en las fincas y en el hogar, especialmente las mujeres, los niños y adolescentes, mientras los hombres adultos participan en las movilizaciones donde se corre riesgo de represión.

Recientemente se ha conformado un Consejo Asesor donde se encuentran las organizaciones que apoyan al movimiento social mediante diversas acciones tales como asesoría, capacitación, comunicación y defensoría legal. De esta forma se distingue el rol de acompañamiento de estas organizaciones, del rol que tienen las instancias propias del movimiento -Consejo Nacional y Comités de Tierras- a las cuales les corresponde la toma de decisiones y la conducción del movimiento social.

El MCITAS se ha mantenido independiente de cualquier afiliación partidaria y ello ha facilitado la integración de campesinos de distinto color político bajo la bandera común de la defensa de sus tierras. Como explica Henry Ruiz, líder de Ometepe y miembro del Consejo Nacional: "La gente ha creído en nosotros porque no estamos en política. Hay políticos que han querido aprovecharse de este movimiento pero la gente los ha rechazado, no pueden hacer proselitismo político en las marchas. Nosotros levantamos el azul y blanco. Yo soy miembro de un partido, pero cuando tomo el micrófono yo no hablo por el partido".

El gobierno Rama Kriol, que representa a las comunidades del Caribe afectadas por el canal, ha presentado un recurso de inconstitucionalidad contra la ley 840 y ha solicitado a la Comisión Interamericana de Derechos Humanos medidas cautelares contra el Estado ante la violación de sus derechos. Sin embargo, algunos líderes y miembros de las comunidades Ramas y Creole han sido cooptados por la empresa y el gobierno ha creado instancias paralelas de esas comunidades para lograr la aprobación del proyecto.

\section{Reflexiones teóricas sobre la dinámica del movimiento}

Los movimientos sociales son un producto de procesos históricos y a la vez productores de cambios sociales, tanto en la sociedad general como dentro del grupo social participante. Un movimiento social surge frente a un conflicto que vulnera sus intereses y que trata de resolverse mediante la movilización cuando no queda otra alternativa. En las últimas décadas se ha desarrollado un debate teórico sobre los movimientos sociales entre quienes enfatizan los factores estructurales y otros que priorizan los elementos socioculturales. En este estudio del MCITAS vemos que 
es preciso tener en cuenta ambos enfoques para comprender mejor su surgimiento y desarrollo.

Diversos estudios señalan que el nacimiento de un movimiento social ocurre cuando existen tensiones estructurales que afloran en coyunturas propicias y son conducidas eficazmente por los actores sociales. Como ha señalado Piotr Sztompka: "Los movimientos sociales se originan en condiciones sociales históricamente específicas, la estructura preexistente constituye un depósito de recursos y de facilidades para el movimiento" (Stompka, 1995, p. 315) Entre las precondiciones históricas y estructurales que permiten comprender el surgimiento del MCITAS, se destacan los siguientes factores:

- La confianza mutua y la solidaridad existentes en las redes sociales a nivel local facilitaron la comunicación y la participación en el MCITAS. En especial se destacan las relaciones entre miembros de familias campesinas extensas que conviven en parcelas cercanas, las vinculaciones entre vecinos de una misma comunidad, las relaciones económicas tejidas a través del comercio y la prestación de servicios, así como la pertenencia a organizaciones comunitarias (equipos deportivos, comités de agua, comités comarcales, proyectos de desarrollo, cooperativas) y la identidad compartida de carácter religioso, étnico o político. En su estudio de los movimientos sociales en América Latina, Salvador Puig destaca que: "Los miembros de los Movimientos Sociales no se movilizan a través de cálculos racionales, ni a partir de decisiones aisladas, sino a través de asociaciones primarias que aportan contacto cara a cara entre aquellos que se profesan confianza” (Puig, 2004, p. 212)

- La memoria histórica del campesinado que compone el actual movimiento social se remonta a las luchas por la tierra que protagonizaron sus antepasados indígenas contra los conquistadores españoles y más tarde contra los terratenientes criollos. También fue netamente campesino el movimiento liderado por A. C. Sandino contra la ocupación yanqui en Nicaragua (1929. 31). A mediados del siglo XX estallaron las luchas campesinas en Chinandega y León contra el despojo de sus tierras por los empresarios del algodón, el banano y la caña. En los años 80 el campesinado quedó en medio del fuego cruzado de los contendientes y fueron campesinos la mayoría de los soldados que lucharon en los dos bandos, y ambos recibieron tierras en las zonas de donde ahora se pretende expulsarlos para construir el canal. En esa década el campesinado se opuso a varias políticas del gobierno sandinista, como la necesidad de formar cooperativas para recibir tierras, la comercialización estatal de granos básicos y el servicio militar obligatorio, razones que explican su voto contra el FSLN en 1990. También en los 80 los pueblos indígenas y afrodescendientes del Caribe lucharon por sus tierras y sus derechos ancestrales, alcanzándose la paz luego de acordar un Estatuto de Autonomía Regional que ha sido desconocido por la concesión canalera (Serra, 1991).

- Las desigualdades de riqueza y poder, sumadas a la exclusión del campesinado en esos municipios donde el 71\% vive en situación de pobreza (INIDE, 2008) 
Encuentro No. 104, 38-52, 2016

ha generado una percepción de injusticia y opresión. Esas precondiciones han facilitado el surgimiento de movimientos contestatarios en diversos países y épocas: "Aquellos privados de oportunidades vitales, de acceso a bienes y recursos, proporcionan una clientela predispuesta a los movimientos sociales" (Stompka, 1995, p. 316).

- El carácter independiente de los productores del campo y de las comunidades indígenas se asocia con su alta valoración de la libertad frente al Estado. Esta autonomía les permite movilizarse con mayor facilidad que un asalariado subordinado a un patrón. Esto ayuda a comprender el alto nivel de participación en el MCITAS de pobladores que habitan en municipios netamente rurales como Nueva Guinea, San Miguelito y Bluefields. En las zonas urbanas la participación en el movimiento social ha sido menor; en esos poblados predominan las actividades comerciales, servicios diversos, empleo en empresas privadas y en instituciones estatales.

- A nivel ideológico hay que señalar que en las últimas décadas se ha desarrollado en muchas zonas del país un proceso de toma de conciencia de los derechos humanos, la participación ciudadana, la organización social, la protección ambiental y el desarrollo sostenible impulsados por cientos de organizaciones civiles. Por otro lado, el discurso del actual gobierno de "pueblo presidente" "poder ciudadano" y "restitución de derechos" se ha convertido en un boomerang ya que el MCITAS le reclama ahora que sea coherente con su discurso y atienda sus demandas.

Por otro lado, hay que considerar las condiciones coyunturales, un conjunto de acontecimientos que contribuyen a que las personas tomen conciencia de sus intereses compartidos y de la posibilidad de alcanzarlos mediante acciones conjuntas. En el surgimiento del MCITAS se pueden señalar los siguientes factores precipitantes:

- $\quad$ El incremento de la polarización y la intolerancia política ocurrido en el país desde el 2006, según muestra una reciente encuesta nacional de cultura política (Coleman \& Maldonado, 2014), ha reabierto las heridas de los 80 en esas zonas campesinas pobladas por quienes adversaron al FSLN durante la guerra. El fraude electoral realizado en esos municipios por el partido de gobierno en los comicios nacionales de 2011 y municipales de 2012 ha teñido de ilegalidad e ilegitimidad ante los ojos de la población a las autoridades y las políticas públicas que ellos aprobaron, especialmente la concesión del proyecto del canal, que no fue consultada con la población afectada.

- Mencionamos el rol jugado por algunas organizaciones y medios en brindar una información alternativa a la propaganda oficial basada en el análisis de la ley 840, en la ejecución de estudios sobre las implicancias ambientales, socio económicas y políticas de la concesión otorgada, así como en el acompañamiento técnico y jurídico brindado al MCITAS. Como señala Blas Zubiría: "La comunicación alternativa es una estrategia vital para que los 
movimientos sociales se consoliden como actores democratizadores y para que tengan impacto global, máxime cuando existen estrategias de dominación para debilitarlos o anularlos, basadas en el dominio de la información, que implementan los Estados así como las grandes cadenas informativas" (Zubiría, 2015).

En un contexto mundial afectado por el cambio climático y por la exclusión de las mayorías, se han multiplicado las demandas en defensa de la ecología y los derechos humanos. El MCITAS ha retomado estos planteamientos que le otorgan un sentido profundo a sus acciones colectivas, abriendo puertas para el ingreso de nuevos miembros y aliados a nivel nacional y mundial. Se destaca la solidaridad de grupos ecologistas de Europa que han presionado a sus gobiernos y a empresas de transporte internacional, como Merk, para que no apoyen este proyecto. Así el MCITAS vincula lo local y lo global; se trata de resistencias populares e indigenas contrahegemónicas que defienden los derechos humanos y el medio ambiente frente a las fuerzas de la globalización capitalista hegemónica que busca maximizar ganancias sin tomar en cuenta la contaminación ambiental y los derechos de las poblaciones (Boaventura de Sousa, 2010).

\section{Conclusiones: resultados y perspectivas}

El proyecto del canal interoceánico y del MCITAS se inscribe dentro de un proceso global de expansión capitalista que intenta abrir nuevos espacios geográficos a la mercantilización, un proceso calificado como 'acumulación por desposesión', ya que interviene territorios donde existen poblaciones con sus identidades culturales, relaciones sociales, prácticas económicas y vinculación con la naturaleza. Esta ofensiva neoliberal ha generado en distintos lugares de América Latina una ola de movimientos socio territoriales frente al capital transnacional y los gobiernos que facilitan su penetración en defensa de sus derechos territoriales y su identidad cultural (López Flores, 2015).

En su análisis de los megaproyectos en América Latina, Martínez plantea que: "Por una parte, observamos a las transnacionales y los gobiernos de distinto tipo que impulsan los grandes proyectos, que tienen como sustento ideológico el mito de la inversión y crecimiento económico con efecto cascada en la distribución de la riqueza; por el otro, comunidades que cada vez se articulan más entre sí para la defensa de sus territorios, de sus recursos naturales y de sus autonomías" (Martínez, 2015). En el caso de gobiernos progresistas como Bolivia, Ecuador o Nicaragua se observa una contradicción entre el discurso democrático, ecológico, anticolonial y estos proyectos de subordinación al capital transnacional que se pretenden imponer al pueblo. Como señala López Flores: "Se verificarían evidentes tendencias de neo colonización de territorios, a través de un relanzamiento y expansión de modalidades de capitalismo de despojo y de continuación/restauración de esquemas monológicos del Estado-nación en la región" (López Flores, 2015, p.11).

$\mathrm{Al}$ evaluar un movimiento social como el MCITAS, que tiene sólo dos años de vida, no se puede pretender el logro de resultados palpables. La valoración de los 
Encuentro №. 104, 38-52, 2016

logros alcanzados por cualquier movimiento social debe tener en cuenta el marco de las posibilidades reales y la correlación de fuerzas existentes, así mismo hay que distinguir efectos de corto, mediano y largo plazo.

Un estudio comparativo de movimientos sociales indica que habría que cumplir seis tareas para tener impacto en la sociedad: conseguir nuevos miembros, mantener la moral y el compromiso de los miembros, el apoyo de grupos externos, la cobertura de medios de comunicación, limitar el control que ejercen los adversarios, e influir en el Estado para que actúe (Mc Adam, 1999). Este estudio muestra que se han cumplido claramente los tres primeros y de forma parcial los tres últimos. En éstos influye el control gubernamental de los medios de comunicación y de todas las instituciones del Estado, sumado al peso numérico de sus seguidores.

Sin embargo, el gobierno no ha podido impedir las protestas públicas y otras acciones del MCITAS. Más aún, el movimiento campesino ha logrado modificar el cronograma de expropiaciones no habiéndose realizado ninguna hasta la fecha, y ha ahuyentado algunos inversionistas internacionales ante la incertidumbre de un proyecto que no ha demostrado su viabilidad financiera, ambiental y social. Internamente, el MCITAS ha ampliado su membresía y sus alianzas, y ha fortalecido su organización de carácter incluyente, apartidario, transparente y democrático.

A primera vista, este movimiento social plantea simplemente un objetivo económico, que es la defensa de sus tierras y propiedades tratando de evitar el cambio que produciría la construcción de un canal y otras inversiones económicas. Por tanto, algunos lo han calificado de un movimiento de carácter "conservador", opuesto al desarrollo y la modernización del país. Sin embargo, la defensa de la tierra y el agua va más allá de la dimensión económica, ya que expresa una identidad cultural específica del campesinado y de las comunidades indígenas caracterizada por una estrecha relación con la naturaleza y un modo de vida particular.

Además, la tierra donde uno ha nacido y vivido es para el campesino la representación concreta de su patria, y siendo una empresa transnacional quien pretende apropiársela, el movimiento asumió un carácter nacionalista en defensa de la soberanía nacional frente al nuevo invasor. Es interesante observar que, mientras el movimiento campesino defiende la patria frente a la amenaza extranjera, los sectores empresariales buscan obtener algún negocio con el canal y los sindicatos de trabajadores tratan de conseguir puestos de trabajo. Como dijo un campesino de Nueva Guinea: "Queremos que el desarrollo lo haga el nicaragüense. Por eso es que lucharon Sandino, Rafaela Herrera, no queremos que sea como Cristóbal Colón que dice que vino a descubrir Centroamérica y lo que hizo fue llevarse todos los tesoros de Nicaragua".

Por otro lado, este movimiento social va más allá de su oposición al cambio y plantea un objetivo político claro de transformación del actual régimen autoritario y centralista en función de un sistema democrático y descentralizado basado en la participación ciudadana en las políticas públicas que los afectan y en la vigencia de derechos humanos reconocidos en la Constitución Política. Como señala Blas Zubiría, este fenómeno se observa actualmente en América Latina: "el papel de los movimientos sociales para transformar los marcos institucionales en que la democracia se consolida, ampliándolos y, a su vez, generando valores y dinámicas de apropiación de lo público que fortalecen dicha democracia, por lo menos en 
términos de inclusión social.... (Además) los movimientos sociales han influido notablemente en la protección de los derechos sociales, políticos y civiles" (Zubiría, 2015, p.1).

Sin duda, el MCITAS ha erosionado la legitimidad del gobierno, particularmente en los municipios que intervendrá HKND, una tendencia que se incrementará al iniciar las expropiaciones y el desplazamiento forzado de la población, ya que un $91.3 \%$ de los nicaragüenses rechazan las expropiaciones aunque sean por razones de interés nacional (Coleman \& Maldonado, 2014).

$\mathrm{Al}$ igual que otros movimientos sociales, el MCITAS enfrenta retos difíciles para alcanzar sus objetivos, a nivel externo, se enfrenta al poder político y económico de sus adversarios. A nivel interno, debe mantener la cohesión y la participación de sus miembros superando las divisiones y el desgaste natural. En esta contienda no sólo está en juego el futuro del campesinado de esos municipios, sino que también depende el futuro de Nicaragua por la trascendencia a nivel nacional que tendrán las concesiones otorgadas al capital transnacional. Por otro lado, hay que recordar que "Las sociedades que suprimen, bloquean o eliminan los movimientos sociales destruyen sus propios mecanismos de auto mejora y auto trascendencia... se convierten en sociedades pasivas de gente ignorante, indiferente e impotente que no tienen oportunidad para cuidar el destino de su sociedad" (Stompka, 1995, p. 324).

\section{Referencias bibliográficas}

Academia de Ciencias de Nicaragua. (2014). El canal interoceánico por Nicaragua: aportes al debate. Managua: Autor.

Asamblea Nacional. (2013). Ley 840 "Ley Especial para el Desarrollo de Infraestructura y Transporte Nicaragüense atingente a El Canal, Zonas de Libre Comercio e Infraestructuras Asociadas" Managua, La Gaceta N¹10.

de Sousa Santos, B. (2010). Refundación del Estado en América Latina. Perspectivas desde una epistemología del Sur. Bogotá: Siglo XXI.

Cardenal. J. P. \& Araujo, H. (2012). La silenciosa conquista china. México: Editorial Paidós.

Centro Humboldt. (2014). Valoraciones Socio Ambientales de la Ruta Seleccionada para la Construcción del Gran Canal Interoceánico por Nicaragua, Managua: Autor.

Centro Nicaragüense de Derechos Humanos. (2014). Informe Derechos Humanos en Nicaragua 2014. Managua: Autor.

Coleman, K.M. \& Maldonado, A. (2014). Cultura política en Nicaragua. Nashville: Vanderbilt University.

Conferencia Episcopal de Nicaragua. (2015). Mensaje para la Cuaresma. Managua, Autor.

Consejo Nacional por la Defensa de Nuestras Tierras, Lago y Soberanía Nacional y Otras Organizaciones. (2015). Construcción del canal interoceánico y su impacto sobre los derechos humanos en Nicaragua. Washington: Comision Interamericana de Derechos Humanos, 16 marzo 2015.

Eyerman, R. \& Jamison, A. (1991). Social Movements: A Cognitive Approach. Cambridge: Polity Press. 
HKND-ERM. (2014). Nicaragua Canal Project Description. Recuperado de http:// hknd-group.com/portal.php? $\bmod =1$ ist\& catid $=46$

HKND-ERM. (2015). Canal de Nicaragua. Estudio de impacto social y ambiental. Resumen Ejecutivo. Recuperado de http://hknd-group.com/portal. php? $\bmod =$ list $\&$ catid $=46$

Ibarra, P. \& Tijerina, J. (1998). Los movimientos sociales: Transformaciones politicas y cambio cultural. Madrid: Editorial Trotta.

Instituto Nicaragüense de Información y Desarrollo. (2008). Municipios en Cifras. Managua: INIDE.

López Baltodano, M. (2014). Recurso por inconstitucionalidad. 25 verdades sobre la concesión del canal interoceánico de Nicaragua. Managua: Popol Na.

López Flores, P.C. (2015) Re-emergencia de conflictos socioterritoriales y movimientos societales en los gobiernos "progresistas" de Bolivia y Ecuador. Ponencia al Congreso de ALAS, San José, Costa Ricas.

Martínez, E.B. (2015). Megaproyectos y disputas por el territorio en América Latina, Ponencia al Congreso de ALAS, San José, Costa Rica.

McAdam, D., McCarthy, Z. M. (1999) Movimientos sociales: perspectivas comparadas. Madrid: Istmo.

Oquist, P. (2013). El gran canal interoceánico de Nicaragua y su impacto en la economía. Managua: Gobierno de Nicaragua.

Osava, M. F. (2013). Megaproyectos en América Latina ¿Para quiénes? IPS en la blogosfera. Recuperado de http://ips.org/blog/esp/megaproyectos-en-americalatina-para-quienes

Puig, S. M. (2004). Los nuevos movimientos sociales en América Latina. En S. M. Puig (ed.) El pulso de América Latina (pp.199-222). Zaragoza: Fundación Paz.

Red Nicaragüense por la Democracia y el Desarrollo Local. (2015). Efectos del canal interoceánico a nivel municipal. Managua. Recuperado de http://www.redlocal. org.ni/

Serra, L. (1991). El movimiento campesino: Su participación política durante la revolución sandinista 1979-1989. Managua: Universidad Centroamericana.

Serra, L. (2003). La participación ciudadana y los movimientos sociales. Encuentro (64), 118-137.

Svampa, M. (2016). Debates latinoamericanos. Indianismo, desarrollo, dependencia y populismo. Buenos Aires: Edhasa.

Tribunal Latinoamericano del Agua. (2016). Resolución sobre el caso del Proyecto de Construcción del Gran Canal Interoceánico. San Salvador 4-8 abril.

Zubiría, M. B. (2015). El papel de los movimientos sociales en los procesos de democratización en América Latina. Ponencia al Congreso de ALAS. San José, Costa Rica. 